\title{
Complementary testing techniques applied to obtain the freeze-thaw resistance of concrete
}

\author{
H.L. Romero, A. Enfedaque, J.C. Gálvez $₫$, M.J. Casati \\ Universidad Politécnica de Madrid, (Madrid, Spain) \\ $\triangle$ jaime.galvez@upm.es
}

Received 28 February 2014

Accepted 24 September 2014

Available on line 29 January 2015

\begin{abstract}
Most of the standards that evaluate the resistance of concrete against freeze-thaw cycles (FTC) are based on the loss of weight due to scaling. Such procedures are useful but do not provide information about the microstructural deterioration of the concrete. The test procedure needs to be stopped after several FTCs for weighing the loss of material by scaling. This paper proposes the use of mercury-intrusion-porosimetry and thermogravimetric analysis for assessing the microstructural damage of concrete during FTCs. Continuous strain measurement can be performed without stopping the FTCs. The combination of the above techniques with the freeze-thaw resistance standards provides better and more precise information about concrete damage. The proposed procedure is applied to an ordinary concrete, a concrete with silica fume addition and one with an air-entraining agent. The test results showed that the three techniques used are suitable and useful to be employed as complementary to the standards.
\end{abstract}

KEYWORDS: Concrete; Freezing-thawing; MIP; Strain measurements

Citation/Citar como: Romero, H.L.; Enfedaque, A.; Gálvez, J.C.; Casati, M.J. (2015) Complementary testing techniques applied to obtain the freeze-thaw resistance of concrete. Mater. Construcc. 65 [317], e048 http://dx.doi.org/10.3989/ mc.2015.01514.

RESUMEN: Resistencia del hormigón frente a ciclos hielo deshielo medida con técnicas complementarias. Las normas para evaluar la resistencia del hormigón a los ciclos hielo-deshielo (CHD) se basan habitualmente en la pérdida de peso por descascarillamiento. Son útiles, pero no proporcionan información sobre el deterioro microestructural del hormigón. Además, exigen detener el ensayo para pesar el material desprendido. Se propone el uso complementario de la porosimetría por intrusión de mercurio y el análisis termogravimétrico para evaluar el daño microestructural del hormigón durante los CHDs. La medida continua de las deformaciones puede hacerse sin detener los CHDs. La combinación de las técnicas enumeradas con las normas de ensayo proporciona información más completa sobre el daño del hormigón. El procedimiento propuesto se aplica a un hormigón convencional, a un hormigón con adición de humo de sílice y a otro con aireante. Los resultados de los ensayos mostraron que las tres técnicas usadas son útiles y adecuadas como complemento a las establecidas en las normas.

PALABRAS CLAVE: Hormigón; Hielo-deshielo; Porosimetría por intrusión de mercurio; Medidas extensométricas

Copyright: (C) 2015 CSIC. This is an open-access article distributed under the terms of the Creative Commons Attribution-Non Commercial (by-nc) Spain 3.0 License.

\section{INTRODUCTION}

The increasing concern about the environmental cost of production of building materials and the impact of construction of civil infrastructure on nature have been taken into account in the newest design recommendations of concrete structures. According to this, the current design lifespan for relevant infrastructure such as bridges has recently been extended to 100 years. Therefore, the design 
of concrete based on durability now plays a leading role in the project stage and construction of structures (1). Among all the possible causes that might decrease the service life of concrete structures in countries with a continental climate, one of the most important is the deterioration caused by freeze-thaw cycles (FTCs). Moreover, the use of de-icing salts in pavements increases the damage induced by the latter (2)

Two kinds of damage can be observed when concrete is subjected to FTCs: scaling of damaged material from the surface of the concrete and internal damage of the concrete. Assessment of durability of concrete is based on the choice of a type of test that reproduces the environment where the structure is located. There are various standards and recommendations that measure scaling resistance, with UNE-CEN/TS 12390-9 (3) being applied in Spain and other European countries. Salt scaling is a damage of the concrete surface caused by freezing of a saline solution on the surface of a concrete body and is one of the major durability issues associated with concrete in freeze-thaw (FT) circumstance. Such damage is progressive and renders the body of concrete susceptible to moisture ingress and aggressive species that threaten overall durability (4).

Both internal and surface damage of concrete can be related with concrete dilation during the FTCs. There are two factors that mainly affect strain in concrete specimens during FTCs: the thermal gradients generated within the specimens and the pore pressure induced by freezing and thawing of the pore water (5). Length change is considered a highly reliable indicator of internal cracking $(6,7)$. Although dilation is possible without microcracking, such microcracking generally accompanies dilation. When there is internal damage induced by pore pressure of concrete specimen, residual strain appears.

The previously explained process might be a reliable indicator of damage in concrete. As deterioration develops, residual strain begins to accumulate. Greater residual strain indicates greater internal damage. As a result, the internal deterioration of a concrete specimen under FTCs might be evaluated by studying the strain increment. Should this be proved, it may be of significant interest if applied to monitor the strain of certain areas of real concrete structures sited in freeze-thaw environments.

As is widely known, the microstructure of concrete is a key factor that determines the mechanical properties of concrete $(8,9)$. This microstructure depends on the composition, constituents, age and curing conditions, among other parameters. While the development of mercury intrusion porosimetry (MIP) has proved to be a suitable technique in studying concrete microstructure, it has not been widely employed in assessing the changes in the microstructure of concrete after FTCs. Moreover, the influence of the FTCs in the hydration process of concrete is a matter that has not been studied yet and is one that nowadays can be ascertained by using thermogravimetric analysis (TG). These three newly developed techniques serve as suitable candidates in extending the analysis and comprehension of the damage induced by the FTCs in concrete elements. In addition, the current recommendations $(3,10,11)$ that deal with this have the main drawback of stopping the test at a certain number of cycles to evaluate the damage in concrete. Through use of some previously mentioned techniques this problem can be overcome.

When employed in concrete air-entraining admixtures (AEA) offer excellent resistance to FTCs, improving plasticity, workability and increasing the durability of the concrete $(12,13)$. However, the use of air-entrained admixtures in bonded prestressed concrete is forbidden because it reduces the bond between steel and concrete. Furthermore, the use of AEA typically decreases the compressive strength of concrete. For these reasons, and in order to find alternative ways to enhance the freeze-thaw resistance of concrete without the use of AEA, some other chemical products have been used in concrete manufacture. An appropriate strategy entails adding silica fume to obtain a finer and closer porous structure, reducing the permeability and improving the mechanical properties of concrete (14-16). Despite this, there are still some doubts about its effectiveness against FTCs (4, 17-20).

This paper shows that the use of mercury intrusion porosimetry and thermogravimetric analysis may be useful for a better understanding of the freeze-thaw microstructural damage of concrete. In addition, continuous strain measurement can be performed without stopping the FTCs. The combination of the above techniques with the freeze-thaw resistance (scaling) standards provides better and more precise information about concrete damage. The proposed procedure is applied to an ordinary concrete $(\mathrm{RC})$, a concrete with silica fume addition (SFC) and one with air-entraining agent (AEC). The tests were performed according to the standards and the number of freeze-thaw cycles was extended beyond their standard duration.

\section{EXPERIMENTAL PROGRAMME}

\subsection{Materials and mixes}

Ordinary Portland cement (OPC) of strength grade $42.5 \mathrm{R}$ and silica fume were employed. The most important components of cement and silica fume are shown in Table 1.

Round siliceous gravel, with diameters ranging from five to $25.4 \mathrm{~mm}$ and with fineness modulus of 7.31 was employed in all formulations as coarse aggregates. 
TABLE 1. Physical properties and chemical composition of cement and silica fume

\begin{tabular}{|c|c|c|c|c|c|c|c|c|c|c|}
\hline \multirow[b]{2}{*}{$\begin{array}{l}\text { Cementitious } \\
\text { Materials }\end{array}$} & \multicolumn{2}{|c|}{ Physical properties } & \multicolumn{8}{|c|}{ Chemical Composition (\%) } \\
\hline & $\begin{array}{c}\text { Fineness } \\
\left(\mathbf{m}^{2} / \mathrm{kg}\right)\end{array}$ & $\begin{array}{c}\text { Specific gravity } \\
\left(\mathbf{k g} / \mathbf{d m}^{3}\right)\end{array}$ & $\mathrm{CaO}$ & $\mathrm{SiO}_{2}$ & $\mathrm{Al}_{2} \mathrm{O}_{3}$ & $\mathrm{Fe}_{2} \mathrm{O}_{3}$ & $\mathrm{SO}_{3}$ & MgO & $\mathbf{K}_{2} \mathbf{O}$ & $\mathrm{Na}_{2} \mathrm{O}$ \\
\hline Cement & 378 & 3.13 & 65.89 & 21.58 & 3.49 & 4.78 & 3.26 & 1.00 & - & - \\
\hline Silica Fume & 20000 & 2.00 & 0.50 & 93.00 & 0.20 & 0.10 & 2.00 & 0.30 & 0.40 & 0.20 \\
\hline
\end{tabular}

River siliceous sand (fineness modulus of 2.87) was chosen as a fine aggregate in all the concrete mixes.

In order to achieve proper workability, a superplasticizer was poured while mixing in all the formulations manufactured. In one formulation an air entraining agent was used. This additive also enhanced concrete workability.

To assess the suitability of MIP, TG and the continuous measurement of strain when applied to concrete subjected to FTC, three types of concrete with different resistance to this kind of environmental exposure were manufactured: One concrete mix containing air entrainment agent (AEC); a second concrete mix with silica fume as a partial replacement of cement (SFC); and a third concrete mix without additives or any cement substitution was performed with ordinary Portland cement (RC). Concretes mixtures had a water/binder materials ratio $(w / \mathrm{cm})$ ranging from 0.40 to 0.45 . All concrete formulations were manufactured using a vertical-axis planetary mixer with a capacity of $100 \mathrm{~L}$. Concrete formulations are presented in Table 2.

\subsection{Specimens and curing}

For each type of concrete, seven cylinder specimens $(\Phi=15 \mathrm{~cm} \mathrm{~h}=30 \mathrm{~cm})$ were cast in typical steel moulds; eight $150 \times 150 \mathrm{~mm}^{2}$ and thickness of $70 \mathrm{~mm}$ prismatic specimens were also cast in steel cube moulds of $150 \mathrm{~mm}$ with a centred vertical plate of methacrylate $(10 \mathrm{~mm})$ which separated the mould into two halves. This process was performed in a laboratory with a temperature of $20^{\circ} \mathrm{C}$. The specimens were demoulded after 24 hours. Once demoulded, cube specimens were placed in a water bath, at $20 \pm 2{ }^{\circ} \mathrm{C}$ temperature for seven days, and then stored in a climate chamber $\left(20^{\circ} \mathrm{C} / 65 \% \mathrm{RH}\right)$ for surface drying for 21 days according to the standard procedures $(3,10,11)$; cylindrical specimens were stored in a climate chamber $\left(20^{\circ} \mathrm{C} / 95 \% \mathrm{RH}\right)$ for 28 days.

\section{DESCRIPTION OF THE TESTING PROCEDURE}

Both fresh and hardened concrete properties were evaluated. In addition, the salt scaling of the concretes had been studied and the results obtained were related with the testing techniques proposed in this work: instead of measuring length changes at certain freeze-thaw cycles, a new continuous strain measure system was developed and applied in order to register the changes of length that take place in the specimens during the cycles. Furthermore, the changes in the microstructure of the three concretes during the FTCs were studied by using mercury intrusion porosimetry (MIP), for assessing the pore structure, performing thermogravimetric (TG) analysis and examining the hydration products.

\subsection{Concrete properties tests}

Slump tests were performed according to the ASTM C 143 standard (21), while air contents in fresh state were determined by pressure meter in accordance to ASTM C 231 procedure (22). Concrete specimens were tested in order to obtain compressive strength at seven and 28 days. In addition, after curing for 28 days the water permeability, tensile strength and their modulus of elasticity were obtained according to widely used and accepted standard tests (23-26).

\subsection{The freeze-thaw test}

Prismatic specimens of three concrete mixes were subjected to FTCs, according to the test method for the freeze-thaw resistance UNE-CEN/TS 12390-9 (3). This regulation is similar to other tests proposed by RILEM $(10,11)$. According to these test procedures, prismatic samples were used to determine the surface scaling. At an age of 21 days, when sufficient hardening is ensured, epoxy resin is glued to

TABLE 2. Concrete mix proportions

\begin{tabular}{lcccccccc}
\hline $\begin{array}{l}\text { Concrete } \\
\mathbf{m i x}\end{array}$ & $\begin{array}{c}\text { Cement } \\
\left(\mathbf{K g} / \mathbf{m}^{3}\right)\end{array}$ & $\begin{array}{c}\text { Silica Fume } \\
\left(\mathbf{K g} / \mathbf{m}^{\mathbf{3}}\right)\end{array}$ & $\begin{array}{c}\text { Sand } \\
\left(\mathbf{K g} / \mathbf{m}^{\mathbf{3}}\right)\end{array}$ & $\begin{array}{c}\mathbf{G r a v e l} \\
\left(\mathbf{K g} / \mathbf{m}^{3}\right)\end{array}$ & $\begin{array}{c}\text { Water } \\
\left(\mathbf{K g} / \mathbf{m}^{3}\right)\end{array}$ & $\begin{array}{c}\text { Superplasticizer } \\
\left(\mathbf{K g} / \mathbf{m}^{3}\right)\end{array}$ & $\begin{array}{c}\text { AEA } \\
\left(\mathbf{K g} / \mathbf{m}^{\mathbf{3}}\right)\end{array}$ & $\begin{array}{c}\text { waterl } \\
\mathbf{b i n d e r}\end{array}$ \\
\hline $\mathrm{RC}$ & 360 & - & 680 & 1160 & 162 & 1.1 & - & 0.45 \\
$\mathrm{SFC}$ & 360 & 40 & 553 & 1239 & 166 & 1.8 & - & 0.42 \\
$\mathrm{AEC}$ & 450 & & 610 & 1190 & 180 & 1.8 & 0.45 & 0.40 \\
\hline
\end{tabular}


all surfaces except the test surface and the opposite. At 72 hours before freezing and thawing, the test surface is filled with fresh water for pre-saturation. During the whole cycles, the specimen was placed in a $3 \% \mathrm{NaCl}$ solution with a height of $10 \mathrm{~mm}$ that left it fully covered. A scheme of the disposition of the samples can be observed in Figure 1.

Then, the specimens were exposed to the freezethaw cycles in a CCK temperature controlled chest. The evolution of temperature vs. time for each freeze-thaw cycle is shown in Figure 2. Starting at $+20^{\circ} \mathrm{C}$, the temperature was lowered in four hours with a constant cooling rate of $10^{\circ} \mathrm{C} / \mathrm{h}$. Once the temperature reached $-20{ }^{\circ} \mathrm{C}$, it was kept constant for three hours and then increased for four hours with a constant heating rate of $10{ }^{\circ} \mathrm{C} / \mathrm{h}$. Finally, it was kept constant for one hour at $+20^{\circ} \mathrm{C}$ to finish the cycle. The total duration of each cycle was 12 hours.

Scaling damage was measured at different intervals of freeze-thaw cycles; following the guide of UNE-CEN/TS 12390-9 (3). During FTCs, the bottom of the specimens was in contact with $3 \% \mathrm{NaCl}$ solution as a freezing medium. The weight of the concrete flakes expelled from the samples was measured immediately after they were removed from the climatic chamber. The total amount of scaled material related to the test surface after the $\mathrm{n}^{\text {th }}$

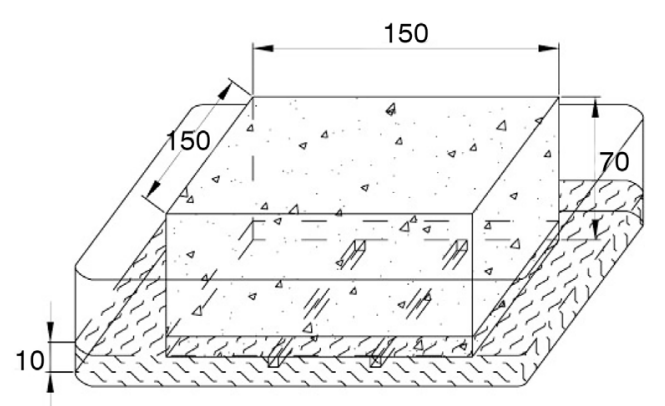

Figure 1. Freeze-thaw test setup. Measurements in mm.

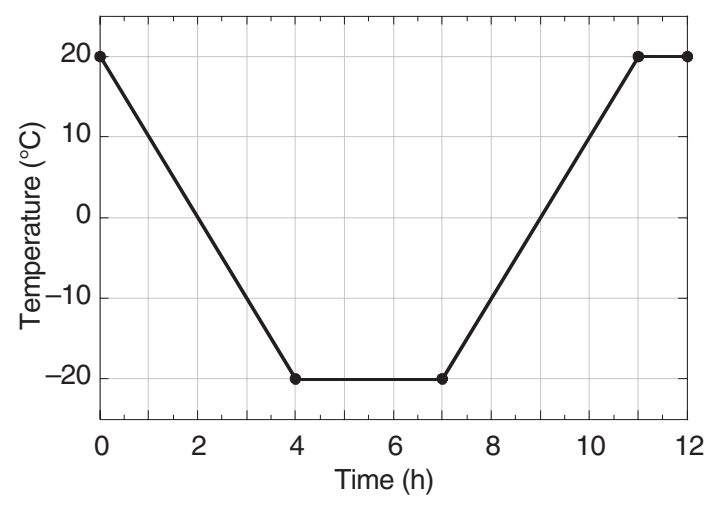

Figure 2. Freeze-thaw cycle. cycle was obtained for each interval and specimen following this relation [1]:

$$
m_{n}=\frac{\Sigma \mu_{s}}{A}
$$

Where $m_{n}$ is the total mass of scaled material related to the test surface after each interval, $\mathrm{g} / \mathrm{m}^{2}$. $\mu_{s}$ is the mass of scaled material at each interval, in $g$ with an accuracy of $0.01 \mathrm{~g}$. $A$ is the area of the test surface, in $\mathrm{m}^{2}$.

\subsection{Strain measurement}

The strain of the surface of the prismatic concrete samples $(150 \times 150 \times 70 \mathrm{~mm})$ during the freeze-thaw cycles was measured through using $50 \mathrm{~mm}$-long commercial strain gauges (HBM, model KLY4150/120). They were glued on the middle part of the lateral surface of the specimens as shown in Figure 3. A covering agent was used to protect the strain gages from humidity and condensed water. After the strain gauges were glued, the lateral surfaces of the specimens were sealed with epoxy resin like the specimens used for the freeze-thaw test. Strain measures were taken each five minutes during the FTCs. The data acquisition system was HBM Quatum X. More details can be found in (27).

\subsection{Porosity by mercury intrusion (MIP)}

MIP tests were performed with a Micromeritics porosimeter, Autopore IV 9500 model, which reached a pressure of $228 \mathrm{MPa}$, and measured the diameter of pores from $0.006 \mu \mathrm{m}$ to $175 \mu \mathrm{m}$. This pressure interval evaluates capillarity and air porosity. Solid specimens between 2-4 g were extracted from the prismatic samples through using a cylindrical head which ensures that there was no damage made to the samples. A sketch of the process carried out to obtain the samples can be seen in Figure 4. In order to observe changes in the porosimetry in relation to the age and freeze-thaw damage, tests were carried out at 28 days

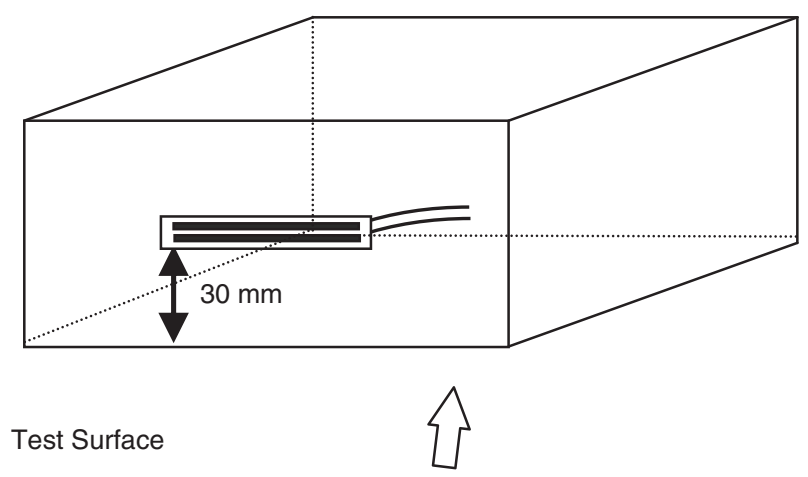

FIgURE 3. Strain measure setup. 

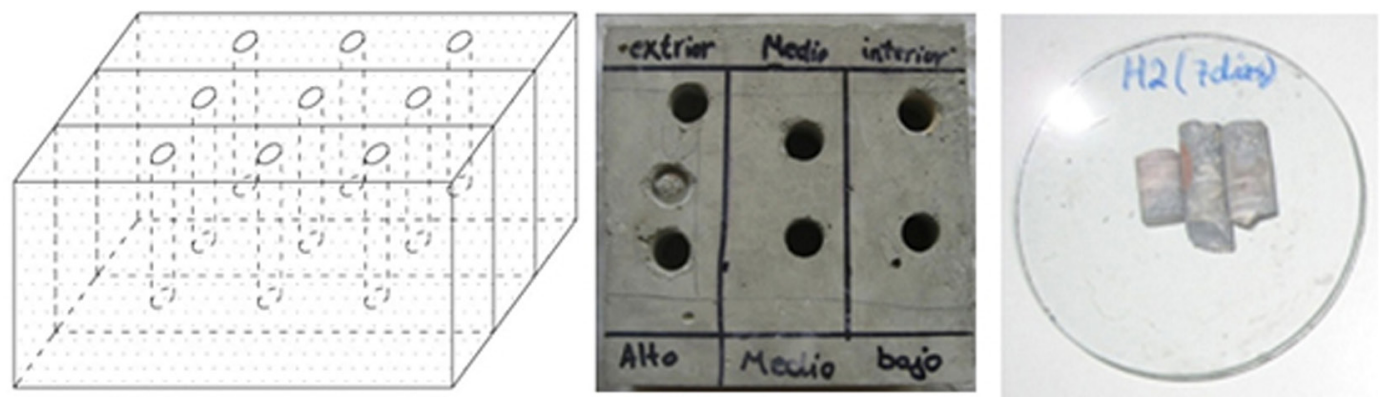

Figure 4. Porosimetry sample extraction.

and after 42 freeze-thaw cycles. Before measurements were taken, all of the specimens were dried at a temperature of $40^{\circ} \mathrm{C}$ until the time of testing. The ASTM D4404-84 (28) standard was adopted.

\subsection{Thermogravimetric analysis (DTG/TG)}

TG tests were carried out with the aim of studying the hydrated compounds generated during hardening, curing and freeze-thaw tests in the three types of concretes. TG is probably the best method for measuring the reduction in calcium hydroxide content and assessing the pozzolanic activity in hardening cementitious materials. Tests were carried out in these concretes before and after 28 freeze-thaw cycles.

The DTG/TG test was performed by using the ASTM E1131: 2008 standard, on thermogravimetric and compositional analysis of solids and liquids. The equipment used was the simultaneous thermal analyser Setaram brand, model Labsys Evo with a balance accurate to $0.1 \mathrm{mg}$. The dynamic heating ramp varied between $40^{\circ} \mathrm{C}$ and $1100{ }^{\circ} \mathrm{C}$. The heating rate was $10{ }^{\circ} \mathrm{C} / \mathrm{min}$ and the crucibles used were made of alumina. The reference material was $\alpha$-alumina $\left(\alpha-\mathrm{Al}_{2} \mathrm{O}_{3}\right)$ previously calcined at $1500{ }^{\circ} \mathrm{C}$. The test was conducted under $\mathrm{N}_{2}$ atmosphere. All tests were made by using approximately $55 \mathrm{mg}$ of previously ground sample.

The hydration of the concrete mixtures was stopped by soaking the samples in methanol for two hours in order to replace the capillary water. To minimise the possible influence of methanol, the samples were dried afterwards in a desiccator over silica gel for one week before testing (29). During the thermogravimetric experiments, all the samples were decomposed in a temperature range from 25 to $1100{ }^{\circ} \mathrm{C}$ at a rate of $10^{\circ} \mathrm{C} / \mathrm{min}$.

\section{RESULTS AND ANALYSIS}

\subsection{The concrete properties}

The results of the slump and air content test are shown in Table 3. Slump test values ranged from 75 to $80 \mathrm{~mm}$. Air content varied between $2.8 \%$ and
$2.6 \%$ for the concretes without entrained air. The effect of the air-entraining agent is observed by the increase of air content up to $7.5 \%$ in AEAC.

Table 4 shows the compressive strength, splitting tensile strength, static modulus of elasticity and water permeability results for each concrete.

SFC had the highest compressive strength, 31\% higher than RC. This effect was caused by the lower w/c ratio and the effect of silica fume in cement hydration reactions. Silica fume particles react with the calcium hydroxide, producing an additional calcium silicate hydrate gel that improves the mechanical properties of concrete. Silica fume not only plays this role, but also alters the microstructure of hydrated cement products, leading to bonds (mainly formed by particles of calcium silicate) with higher strength between cement matrix and the aggregate $(14,19)$.

AEC had higher compressive strength than RC. These results point out that even though AEC concretes suffer the deleterious effect of air-entraining additives (30), the higher w/c ratio and the lower cement content of $\mathrm{RC}$ has a greater influence on compressive strength. The density reduction of concrete caused by the air bubbles in concrete does not counterweight the differences in water/binder.

TABLE 3. Concrete fresh properties

\begin{tabular}{lcc}
\hline Concrete mix & Slump (mm) & Air content (\%) \\
\hline RC & 75 & 2.6 \\
SFC & 80 & 2.8 \\
AEC & 80 & 7.5 \\
\hline
\end{tabular}

TABLE 4. Concrete properties

\begin{tabular}{lrrr}
\hline Properties & RC & SFC & AEC \\
\hline Compressive strength seven days (MPa) & 24.2 & 38.5 & 28.0 \\
Compressive strength 28 days (MPa) & 28.5 & 41.5 & 32.4 \\
Tensile strength (MPa) & 2.9 & 3.9 & 3.1 \\
Modulus of elasticity (GPa) & 26.2 & 29.0 & 26.2 \\
\hline
\end{tabular}


The indirect tensile strength test showed the same trends as those previously mentioned for compressive strength. There were significant differences between SFC and the rest of concretes while between AEC and RC there were only differences of $8 \%$. Similar values of the modulus of elasticity of the different concrete mixes were obtained. As expected, and due to the densifying effect of silica fume particles, SFC was stiffer than the rest of concretes though there was only a slight variation of $10 \%$ between the modulus of elasticity of RC and SFC (30).

\subsection{Permeability}

Permeability tests were performed in one cylindrical $15 \varnothing \times 30 \mathrm{~cm}$ specimen of each formulation in accordance with the EN 12390-8 standard (24). Water applied pressure was $500 \mathrm{kPa}$ for three days. Afterwards, the sample was split by means of an indirect tensile test and the depth profile of water measured.

Silica fume improves concrete in two ways: it promotes the pozzolanic reactions that take place during cement hydration and, due to the small size of its particles, also acts as microfiller. Silica fume particles, due to an extremely small size, are able to occupy small voids in the concrete microstructure. This phenomenon reduces the permeability of concrete; it improves the paste to aggregate bond and also increases the density of the cement matrix (31). As expected, the concrete manufactured with silica fume addition was less permeable than $\mathrm{RC}$ as can be seen in Table 5.

Entrained air in concrete produces discrete nearly spherical bubbles in the cement paste. These are approximately 50 micrometer in diameter and result in the formation of extremely few channels for the flow of water and an insignificant increase in permeability $(32,33)$. This effect has been observed in concrete with air entraining agent where a minor decrease in concrete permeability was noted, as can be seen in Table 5 .

\subsection{Scaling}

The measured cumulative scaling after four, six, 14 and 28 freeze-thaw cycles according to UNE-CEN/TS 12390-9 EX (3) is shown in Figure 5 where a clear deterioration of the RC can be

TABLE 5. Water penetration in concrete

\begin{tabular}{lc}
\hline Concrete mix & Water Permeability-Penetration depth (mm) \\
\hline RC & 13.8 \\
SFC & 11.8 \\
AEC & 10.8 \\
\hline
\end{tabular}

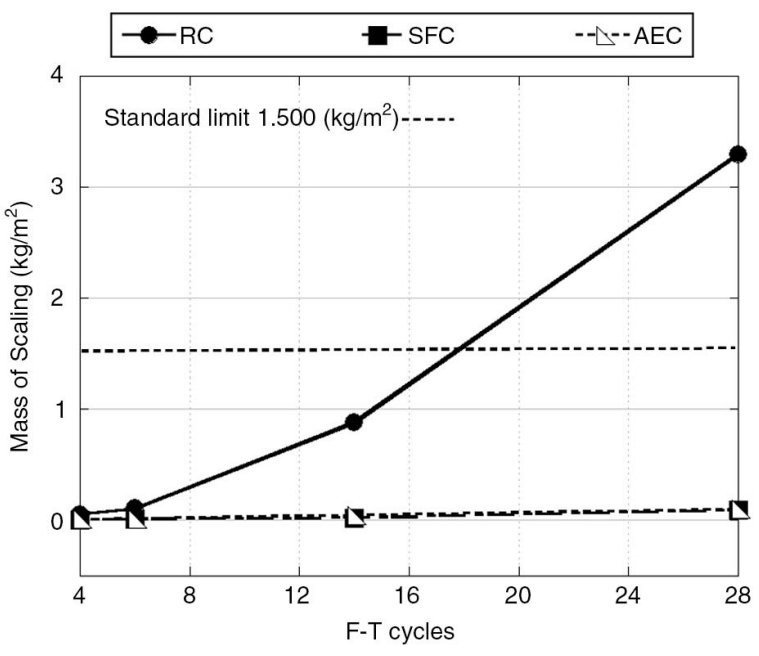

FIgURE 5. Cumulative Scaling during 28 Freeze-thaw cycles.

observed. Damage in RC starts from cycle 6 and increases monotonically during the rest of the cycles. After 28 cycles RC exceeds the standard limit of the scaling established in recommendations $\left(1.5 \mathrm{~kg} / \mathrm{m}^{2}\right)$ over $120 \%$. According to the standard test, SFC and AEC concrete formulations can be considered as freeze-thaw resistant concretes.

These results can be visually confirmed by comparison of the photographs of the test surfaces of the concrete samples shown in Figure 6.

However, extension of the duration of the test beyond the 28 freeze-thaw cycles stated by this standard test procedure was considered of interest. Previous studies (30) pointed out that SFC freezethaw resistance was highly influenced by the amount of cycles, and that the behaviour of the different types of concrete might change with freeze-thaw exposure. In order to determine the behaviour of concrete when subjected to long periods of freezethaw environments, the duration of the tests was extended to 70 cycles.

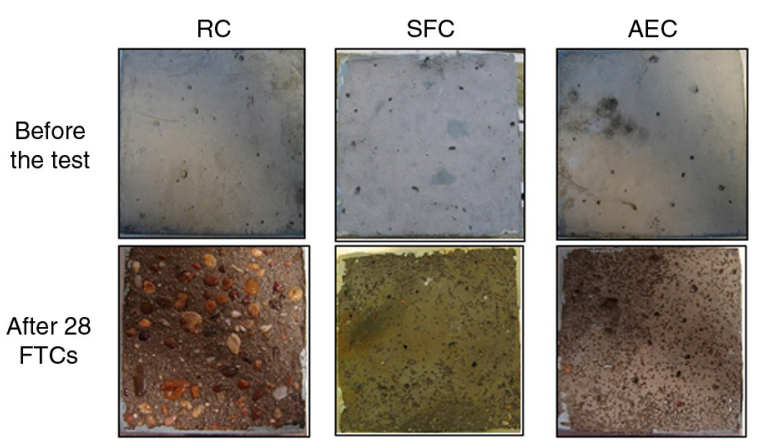

FIGURE 6. Test surfaces of concrete specimens before and after 28 freeze-thaw cycles. 
Figure 7 shows the cumulative scaling during 70 cycles. There are evident differences among the behaviours of the concretes tested. As expected, AEC showed no significant damage. Whereas the air bubbles created by the air-entraining additive reduced the bleeding of concrete, the ice in the air voids sucked pore fluid from the surrounding matrix which led to a compression of the porous body $(4,34)$. Freeze-thaw resistance of the air-entrained concrete formulations was remarkable. RC formulation continued to be damaged by freeze-thaw cycles throughout the test. Scaling increased monotonically and almost at a constant ratio between six and 70 cycles.

However, and in contrast with the widely known tendencies observed in RC and AEC, the behaviour of SFC showed a clear change immediately after exceeding 28 cycles. The scaling/cycle ratio rose continuously between $28-42,42-56$ and 56-70 cycles. Upon finishing the 70 cycles, SFC registered a higher degree of damage than RC.

Previous studies have pointed out that silica fume increases the early strength of concrete. In Table 4, the influence of silica fume particles on compressive strength can be observed. This improvement is caused by a reduction of porosity (35) and a rise in the fracture toughness of the interfacial transition zone (36). Both effects are a consequence of a better packing of the cement mortar hydration products which also might improve the scaling resistance (5). This statement is valid when SFC is subjected to medium-term exposures to freeze-thaw cycles. Under 28 cycles, only slight scaling was noticeable in SFC.

However, after cycle 28 the damage of the surface of SFC samples starts. A slight increment of the scaling/cycle ratio that promotes the damage in the sample until cycle 42 is identifiable. This tendency continued, and was even amplified, between cycle 42

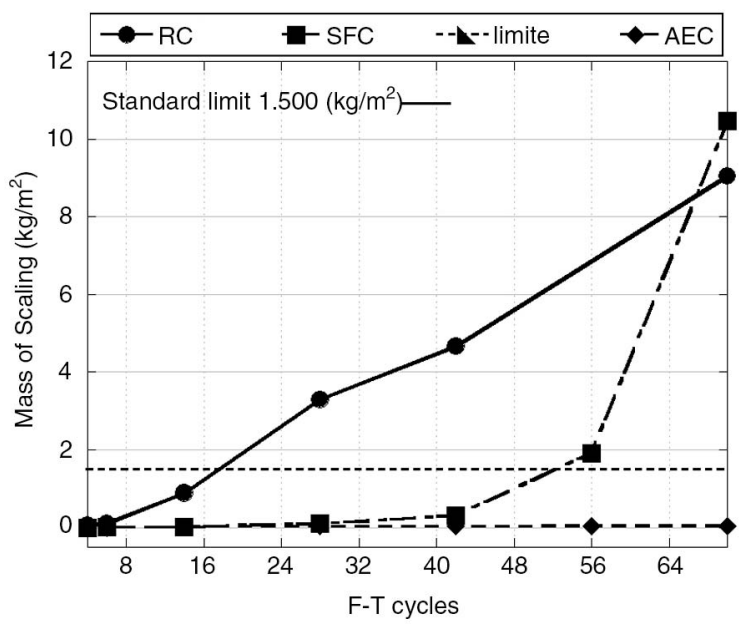

FIGURE 7. Scaling after 70 cycles. and 56. This phenomenon was also evident between cycles 56 and 70, increasing the cycle/damage ratio rapidly. The scaling ratio is so steep that the cumulative scaling at the end of the 70 cycles in SFC exceeded the RC values.

This is also confirmed in Figure 8 where the tested surface of a SFC after 70 freeze-thaw cycles can be compared with those from RC and AEC. The SFC tested surface was completely deteriorated by the freeze-thaw cycles and coarse aggregates exposed. There were some empty spaces in the samples, given the removal of some coarse aggregates. This appearance confirmed the tendency showed in Figure 7.

\subsection{Strain measurement}

In Figure 9 the behaviour of the samples of the three types of concrete studied can be seen. It is clear that there are compressive strains when the temperature is decreasing, while concrete expands when the temperature is increased. This behaviour is in accordance with the theories that explain this phenomenon and with results of many researchers (37-40).

Strains were registered continuously only during the first 56 cycles, as the damage induced by freezethaw cycles reached the strain gauges position and the gauges were peeled off from the surface of the RC and SFC samples. For the sake of clarity the continuous measurement of strain has been replaced
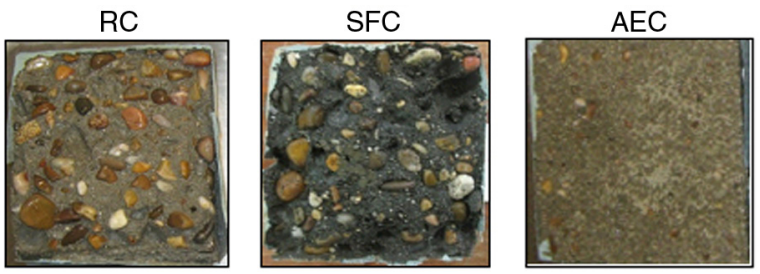

FIGURE 8. Test surfaces of concrete specimens after 70 FTCs.

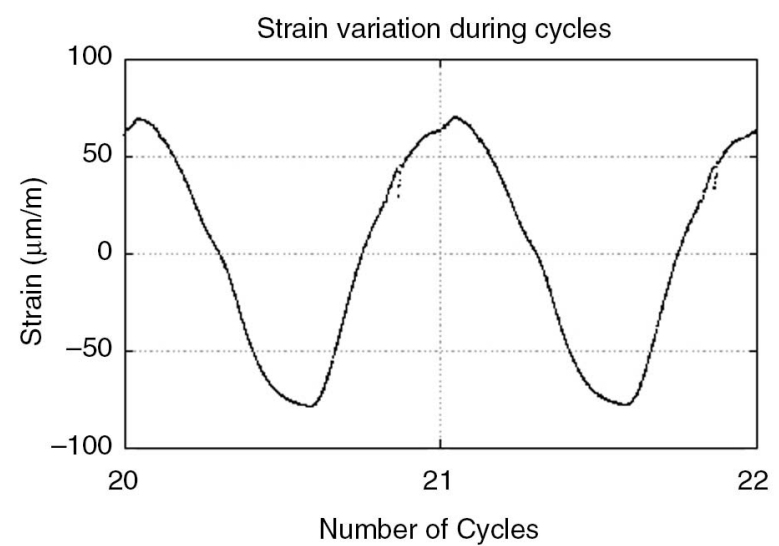

FIGURE 9. Strain registered during two cycles. 
in Figure 10 by the tendencies of the curves registered. The behaviour of the surface strain evolution of the three types of concretes can be seen in Figure 10. A change in the total strain of samples was only noticed in those samples where the damage of the surface had also occurred. The trends shown in Figure 10 confirmed the results of scaling tests showed in Figure 7 and the appearance of the samples shown in Figure 6.

In RC between cycle 0 and 4 microcracks appear in the tested surface which shows a noticeable length change, as can be seen in Figure 10, although there is no evidence of scaling. Once microcracks were created they grew from the tested surface to the opposite one and coalesced, increasing the total length of the sample and generating damage of the surface of the samples which happened from cycle 4 onwards. This process continued during all the cycles and the length of the RC samples, with mass scaling increasing at a constant ratio, as can be confirmed in Figure 5 and Figure 7. By comparing Figure 10 with Figure 5 and Figure 7, it is clear that not only is the strain measurement capable of registering the beginning of the damage, but also the rate of damage/cycle. In addition, the strain measurement performed was more precise and sensitive than the usual length measurement proposed by the recommendations cited $(3,10,11,27)$. Resolution for strain gage was $1 \mu \mathrm{m}$, being $0.01 \mathrm{~mm}$ for the mechanical gauge. The permanent strain in $\mathrm{RC}$ increased monotonically, with the strain/cycle ratio being considered constant similarly to the scaling ratio that appears in Figure 7.

No permanent strains were registered by the gauges in any cycle of the freeze-thaw test in the AEC specimens.

As can be seen in Figure 10 the strain/cycle ratio of SFC changed as the test advanced, as happened in the scaling/cycle ratio. The differences in this ratio between RC and SFC were caused by the different damaging mechanisms that took place in $\mathrm{RC}$ and SFC. In RC freeze-thaw cycles there was damage of the concrete surface from almost the beginning of

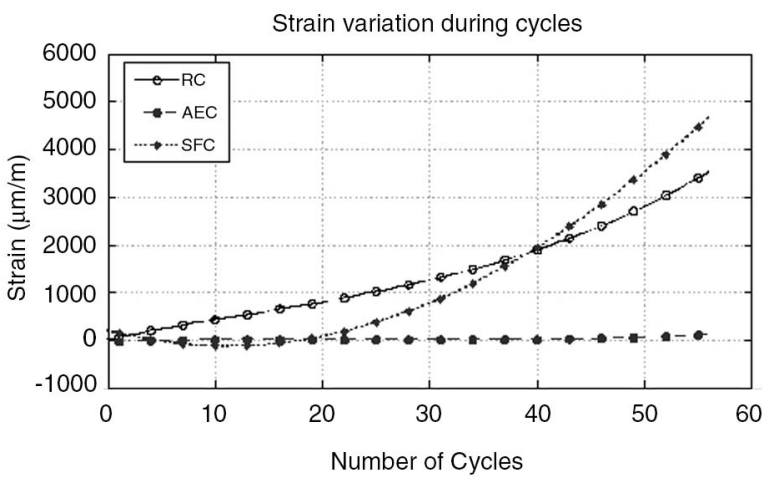

FIGURE 10. Strain measurements. the tests. From such damage, cracks grew inwards and scaling was produced. However, while in SFC no damage of the surface was observed during the first cycles internal damage did occur. These mechanisms have been previously studied by different authors in comparisons of the evolution of RDME and surface scaling in SFC and RC formulations $(7,13,30)$.

While SFC internal damage does not either cause an increment of strain or scaling in the first 20 cycles of the test, microcracks appear inside the sample. Once microcracks are widespread and distributed in the sample and the tested surface damaged, cracks from the tested surface grow rapidly from it into the sample and coalesce with the microcracks previously generated. Therefore, damage evolution (strain increments and scaling) occurred at higher ratios because the cement matrix was previously damaged. The strain/cycle ratio changed between cycle 20 and 30 and was constant beyond. The scaling/cycle ratio continued to grow as the test continued, with the reason being that the distance between the crack lips grew and the volume of the damaged sample therefore increased. These effects were registered by the continuous measurement of the strains of the samples.

\subsection{Porosity by mercury intrusion}

A detailed study on the changes of the porous network of all formulations was carried out by using MIP tests, before the start of freeze-thaw test at 28 days and after 42 FTCs. The evolution of the total porosity, critical pore diameter and average pore diameter are shown in Table 6 . The critical pore diameter is the size of the interconnected pore that is continuously repeated. The average pore diameter is the diameter found by assuming an equivalent pore distribution and is related to the pore connectivity (41).

The evolution of the pore distribution of the concrete formulations before and after the freezethaw cycles is shown in Figures 11, 12 and 13. According to Figure 11, there were substantial changes in the microstructure of RC. The smaller pores (from $1.10^{1}$ to $1.10^{2} \mathrm{~nm}$ ) were slightly affected by the freeze-thaw cycles and the hydration of the cement paste and the volume of mercury intruded almost constant after FTCs. However, in the results obtained after the freeze-thaw cycles two peaks appeared between $1.10^{2} \mathrm{~nm}$ and $4.10^{2} \mathrm{~nm}$ and at $3.10^{3} \mathrm{~nm}$. These peaks might have been caused by the cracks that appeared in the cement paste as a result of the pressures induced in the samples by the change in volume of water when icing. In addition, the total volume intruded is greater after the cycles as can be seen in Table 6 . The average pore size has also increased because the amount of small pores remained constant while the amount bigger pores or cracks grew, with the critical pore diameter 
TABLE 6. Analysis results of porosity and pore characteristics according to the types of concrete

\begin{tabular}{lcccccccc}
\hline & \multicolumn{2}{c}{ Total Porosity $(\mathbf{\%})$} & & \multicolumn{2}{c}{ Critical diameter $(\mathbf{n m})$} & & \multicolumn{2}{c}{ Average pore diameter $(\mathbf{n m})$} \\
\cline { 2 - 3 } \cline { 8 - 9 } Concrete mix & $\mathbf{2 8}$ days & after F-T & & $\mathbf{2 8}$ days & after F-T & & 28 days & after F-T \\
\hline RC & 15.05 & 17.85 & & 64.30 & 62.30 & & $3.69 \mathrm{E}-02$ & $4.65 \mathrm{E}-02$ \\
SFC & 9.01 & 13.25 & & 40.00 & 17.96 & & $3.39 \mathrm{E}-02$ & $2.89 \mathrm{E}-02$ \\
AEC & 13.87 & 15.92 & & 62.88 & 51.03 & & $5.12 \mathrm{E}-02$ & $4.53 \mathrm{E}-02$ \\
\hline
\end{tabular}

remaining the same. This effect might have been caused either because the cracks were not connected or because the amount of cracks connected were outnumbered by the connected small size pores.

The volume of mercury intruded is the area under the porosimetry results shown in Figures 11, 12 , and 13 . The effect of the small particles of silica fume in SFC porosimetry results can be noted in

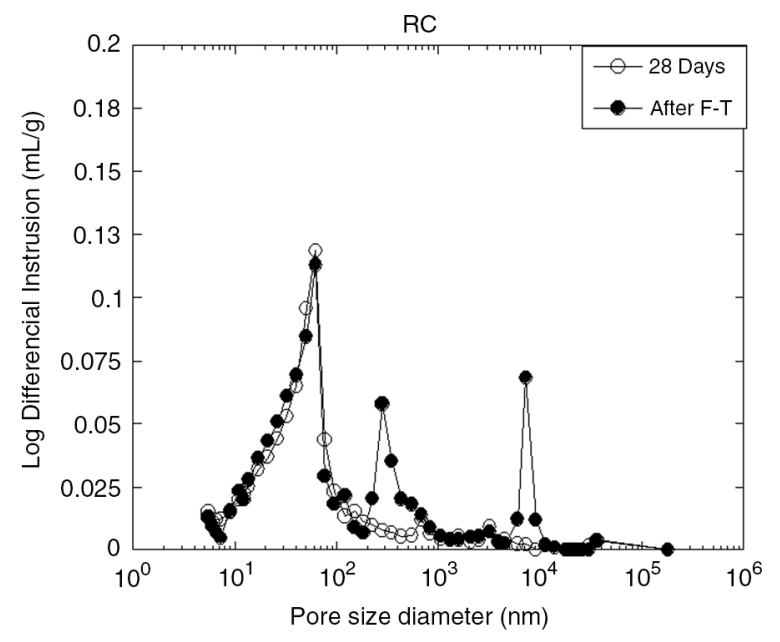

Figure 11. Pore size distribution of RC.

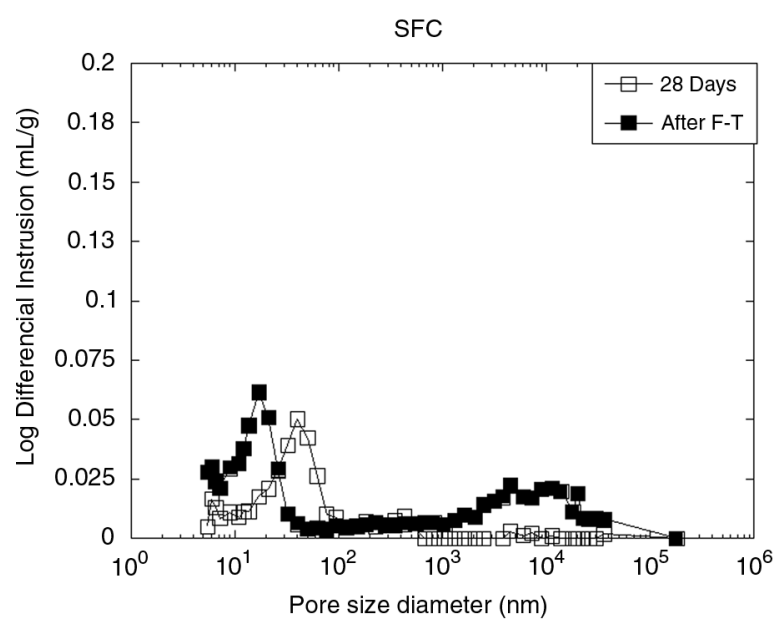

FIGURE 12. Pore size distribution of SFC.
Figure 12. The volume of mercury intruded in the pores was significantly lower than that intruded in $\mathrm{RC}$, as can be seen by comparing the area under the curves of Figures 11 and 12. Silica fume has an average particle size of less the one micron (100 times finer than cement). These fine particles fill the gaps between cement grains and react with free lime released during cement hydration. This produces strong calcium silicate hydrates to replace weak lime and voids found in normal concrete. For this reason, the addition of silica fume significantly reduces the total porosity of the cement paste.

After 42 freeze-thaw cycles there were significant differences in the results obtained in MIP tests when compared with those obtained at 28 days (before the FTCs). As the left part of the curve, which represents the smaller fraction of pores (between $3.10^{\circ}$ and $2.10^{2} \mathrm{~nm}$ ), shifted to the left the diameter of these pores were reduced. However, the amount of pores of the biggest diameters increased dramatically. This increment can be attributed to the cracks that appeared during the freeze-thaw tests. This result is in accordance with the results of those previously obtained (42). It is also important to highlight that after FTCs the cracks generated in SFC samples ranged from $10^{3}$ to $10^{5} \mathrm{~nm}$.

During the cycles, the hydration reactions continued to take place in cement paste that led to a

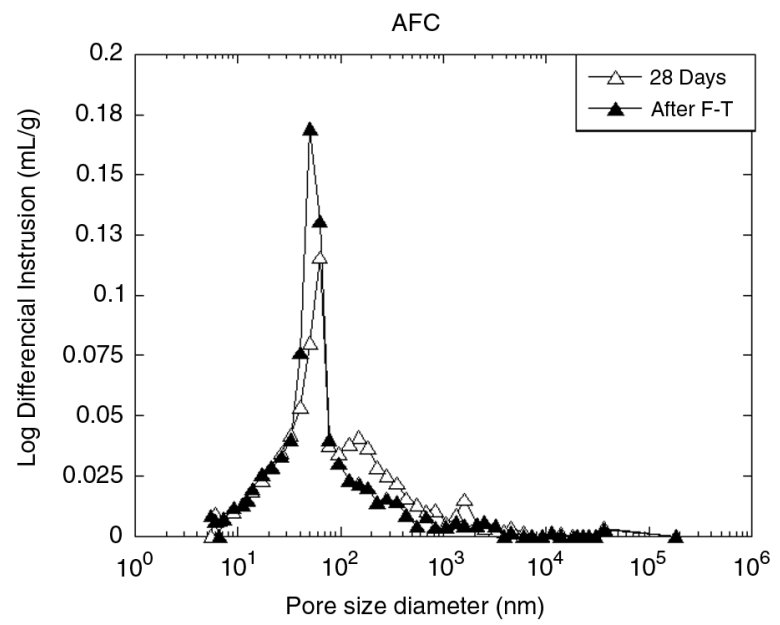

FIGURE 13. Pore size distribution of AEC. 
reduction in the diameter of the pores. As a result of this hydration process, the critical diameter of the pores was smaller than before the cycles. Furthermore, the average diameter was smaller than before the cycles. The effect of the cement compounds hydrated during the cycles outbalanced that of the cracks induced by ice during the freeze-thaw test.

Only slight differences were found when comparing the MIP results before and after the freeze-thaw cycles in AEC as shown in Figure 13. The critical diameter and the average diameter were smaller after the freeze-thaw cycles for AEC, as can be expected due to the hydration of the cement that took place during the freeze-thaw cycles. Air-entraining improves the frost resistance of concrete by providing expansion space in the cement paste for the freezing water. In addition, it also modifies the transition zone around the aggregate to permit the expulsion of water from the aggregate pores (19).

\subsection{Thermogravimetric analysis}

In the DTG/TG tests the components of the paste are decomposed in a certain range of temperatures while heating. This temperature is characteristic for each chemical component. The amount of mass loss is determined using the TG curve. To assess the beginning and the end of a decomposing process the DTG curve (derivative curve of TG) is employed. The peak areas of the DTG curve that can be seen in Figure 14 comprised the temperatures where the compound is being decomposed.

As can be seen in Figure 14 the results of the DTG/TG typically show three zones. The first zone, delimited by 100 and $300{ }^{\circ} \mathrm{C}$, was attributed to the dehydration of $\mathrm{C}-\mathrm{S}-\mathrm{H}$ and ettringite. The temperature at which these compounds lose water depends on the available $\mathrm{CaO} / \mathrm{SiO}_{2}$ ratio in the hydrated cement matrix. The second zone covers the range between 290 and $350{ }^{\circ} \mathrm{C}$, characterising the decomposition of calcium aluminate silicate hydrate, calcium aluminate

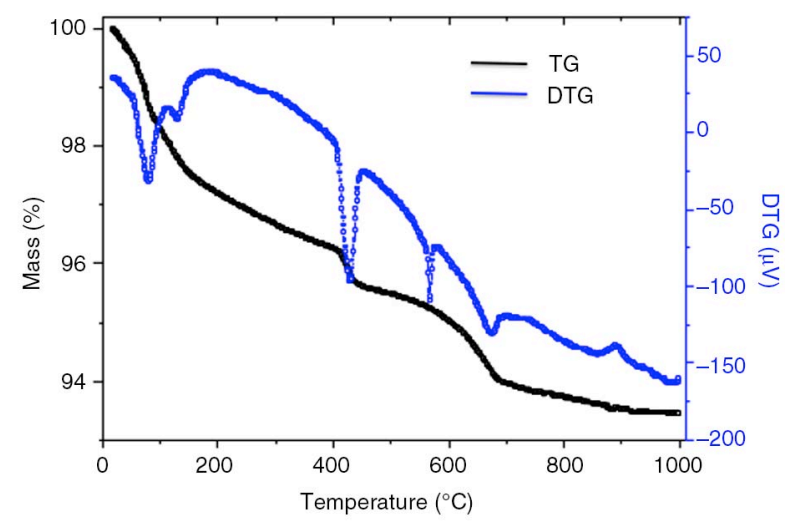

FIGURE 14. DTG/TG analysis of a standard concrete. hydrate and calcium chloroaluminate (43). Finally, the third area, which ranged from 450 to $510^{\circ} \mathrm{C}$, was attributed to the dehydration of calcium hydroxide. An endotherm around $700{ }^{\circ} \mathrm{C}$ indicated the decarbonation of calcium carbonate in the hydrated compound (44). Through use of the data gathered in the tests, the hydration products of the three types of concrete were obtained, as can be seen in Table 7. In addition, the degree of cement hydration is shown in Figure 15. The test results show that the hydration process continued during the freeze-thaw process in all concrete formulations. The increase of cement hydration is higher in AEC and SFC specimens than in $\mathrm{RC}$ samples. The obtained hydration process continuation confirmed the refinement of the smaller sizes of the pore structure observed in MIP tests.

The comparison of the results before and after FCTs show that, for the three concretes, water gel, portlandite content and the degree of hydration increased during FCTs. Which is a consequence of the normal evolution of the hydration of concrete. The concrete with air entrained agent (AEC) showed higher content of gel, portlandite and a significant increase in the degree of hydration of concrete due to freeze-thaw cycles. Which may be caused by the higher content of cement and the modified network of pores generated by the air bubbles that help to maintain more water inside the concrete. This aspect should be studied in depth and it is out of the scope of this paper.

\section{CONCLUSIONS}

All the data gathered in this study open the spectrum to a new way of monitoring concrete structures. By using strain gauges, a continuous measurement of the harmful consequences of the freeze-thaw cycles in the structure can be performed. Such measurement can be correlated with laboratory results obtaining precise information of the residual resistance of the concrete element to the environment. In sites where a continuous monitoring of the structure cannot be introduced, the onset of the damage can be determined by performing PIM analysis as has been shown. This early detection of damage would allow taking actions to prevent further damage.

According to the results, silica fume addition generates concretes capable of being subjected to midterm freeze-thaw exposition without being damaged. However, silica fume additions do not avoid either the internal or the damage of the surface introduced by long-term freeze-thaw environments and are even more damaged that RC. The damaging processes of freezing environments act faster in concrete manufactured with silica fume once the damaging effects have appeared.

Strain measurement is a reliable and easy parameter in evaluating concrete resistance to freeze-thaw environments. There is a clear correlation between 
TABLE 7. Evolution of hydration products according to the types of concrete

\begin{tabular}{|c|c|c|c|c|c|c|}
\hline \multirow[b]{2}{*}{ Product } & \multicolumn{2}{|c|}{$\mathbf{R C}$} & \multicolumn{2}{|c|}{ AEC } & \multicolumn{2}{|c|}{ SFC } \\
\hline & Before FTCs & After FTCs & Before FTCs & After FTCs & Before FTCs & After FTCs \\
\hline Gel & 12.31 & 12.89 & 12.08 & 16.03 & 11.70 & 14.52 \\
\hline Portlandite & 20.26 & 21.00 & 20.02 & 24.97 & 15.70 & 21.22 \\
\hline Hydration degree & 61.04 & 64.36 & 59.72 & 82.99 & 57.62 & 73.86 \\
\hline
\end{tabular}

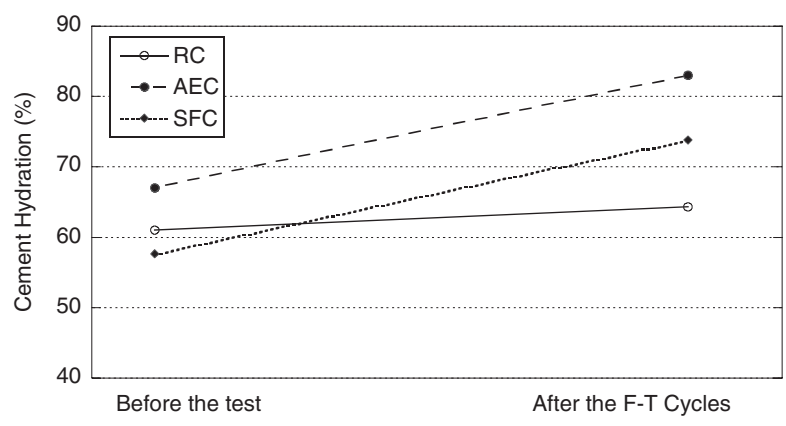

FIGURE 15. Degree of cement hydration in the three concrete mixes.

strain measurements and scaling. Results obtained for both parameters have proved to be consistent. In addition, continuous measurement of strain avoids possible human errors in manual length measurements. This technique is shown as being viable and provides advantages over the weight of the mass released by peeling surface.

Porosimetry techniques have revealed the differences in the porous network of the three types of concrete. Frost damaging effects have been clearly observed by comparing porosimetry tests results before and after the freeze-thaw cycles in RC and SFC. Air entraining agents did not affect the connected pore network of concrete. TG results confirmed the results of the MIP tests. The hydration process of cement continued even during FTCs, refining the smallest sizes of the pore structure of concrete. As expected AEC enhance the concrete scaling resistance even in long-term expositions to FTCs.

\section{ACKNOWLEDGMENTS}

The authors gratefully acknowledge the financial support for the research provided by the Spanish Ministerio de Economía y Competitividad under grant DPI2011-24876. H.L. Romero also wishes to express his gratitude to the Fundación Agustín de Betancourt for the grant provided.

\section{REFERENCES}

1. Ho, E.; Gough, W.A. (2006) Freeze thaw in Toronto, Canada in a changing climate. Theoretical and Applied Climatology, 83, 203-210. http://dx.doi.org/10.1007/s00704-005-0167-7.
2. Mays, G. (2003) Durability of Concrete Structures, Investigation, Repair and Protection, Taylor \& Francis, London.

3. UNE-CEN/TS 12390-9 EX (2008). Freeze-thaw resistance, surface mass loss.

4. Valenza, II, J.J.; Scherer, G.W. (2007) A review of salt scaling: I. Phenomenology. Cem. Concr Res. 37, 1007-1021. http://dx.doi.org/10.1016/j.cemconres.2007.03.005.

5. Sahin, R.; Tasdemir, M.A.; Gül, R.; Celik, C. (2007) Optimization Study and Damage Evaluation in Concrete Mixtures Exposed to Slow Freeze-Thaw Cycles. Journal of Materials in Civil Engineering ASCE, 609-615. http:// dx.doi.org/10.1061/(ASCE)0899-1561(2007)19:7(609).

6. Mao, J.; Ayuta, K. (2008), Freeze-Thaw Resistance of Lightweight Concrete and Aggregate at Different Freezing Rates. Journal of Materials in Civil Engineering ASCE, 20, 78-84. http://dx.doi.org/10.1061/(ASCE)0899-1561(2008) 20:1(78).

7. Dombrowski, K.I.; Erfurt, W.; Janssen, D. (2002) Identifying D-cracking susceptible aggregates-a comparison of testing procedures. Proceedings Frost damage in Concrete, RILEM, 221-232.

8. Van Mier, J.G.M.; Van Vliet, M.R.A. (2003) Influence of microstructure of concrete on size/scale effects in tensile fracture. Engineering Fracture Mechanics, 70 [16], 2281-2306. http://dx.doi.org/10.1016/S0013-7944(02)00222-9.

9. Uchikawa, H.; Hanehara, S.; Hirao, H. (1996) Influence of microstructure on the physical properties of concrete prepared by substituting mineral powder for part of fine aggregate. Cem. Concr. Res. 26 [1], 101-111. http://dx.doi. org/10.1016/0008-8846(95)00193-X.

10. RILEM TC 117 FDC (1995) Draft Recommendation for Test method for the freeze- Thaw Resistance of ConcreteTest with water (CF) of with sodium chloride solution (CDF). Materials and Structures 28, 175-182.

11. RILEM TC 176-IDC (2004) Test methods of frost resistance of concrete: CIF-Test: Capillary suction, internal damage and freeze thaw test Reference method and alternative methods A and B. Materials and Structures, 37, 743-753.

12. Lomboy, G.; Wang, K. (2009) Effects of Strength, Permeability, and Air void Parameters on Freezing-Thawing Resistance of Concrete with and without Air Entrainment. Journal of ASTM International, 6 [10]. http://dx.doi.org/ 10.1520/JAI102454

13. Sabir, B.B.; Kouyiali, K. (1991) Freeze-Thaw Durability of Air Entrained CSF Concrete. Cem. Concr. Comp. 13, 203-208. http://dx.doi.org/10.1016/0958-9465(91)90021-9.

14. Toutanji, H.; Delatte, N.; Aggoun, S.; Duval, R.; Danson, A. (2004) Effect of supplementary cementitious materials on the compressive strength and durability of short-term cured concrete. Cem. Concr. Res. 34, 311-319. http://dx.doi. org/10.1016/j.cemconres.2003.08.017.

15. Appa Rao, G. (2001) Influence of silica fume on long-term strength of mortars containing different aggregate fractions. Cem. Concr. Res. 31, 7-12. http://dx.doi.org/10.1016/ S0008-8846(00)00346-X.

16. Yacizi, H. (2008) The effect of silica fume and high-volume Class $\mathrm{C}$ fly ash on mechanical properties, chloride penetration and freeze- thaw resistance of self-compacting concrete. Constr. Build. Mater. 22, 456-462. http://dx.doi. org/10.1016/j.conbuildmat.2007.01.002.

17. Jacobsen, S.; Sœther, D.H.; Sellevold, E.J. (1997) Frost testing of high strength concrete: frost/salt scaling at different 
cooling rates. Materials and Structures, 30, 33-42. http:// dx.doi.org/10.1007/BF02498738.

18. Persson, B. (2003) Internal frost resistance and salt frost scaling of self-compacting concrete. Cem. Concr. Res. 33, 373-379. http://dx.doi.org/10.1016/S0008-8846(02)00968-7.

19. Kreisel, R.C.; French, C.E.; Snyder, M.B. (1998) FreezeThaw Durability of high-Strength Concrete. Technical final report, Dept. of Civil Engineering, University of Minnesota.

20. Al-Assadi, G.; Casati, M.J.; Fernández, J.; Gálvez, J.C. (2011) Effect of the curing conditions of concrete on the behaviour under freeze-thaw cycles. Fatigue and Fracture of Engineering Materials and Structures, 34 [7], 461-469. http://dx.doi.org/10.1111/j.1460-2695.2010.01520.x.

21. ASTM C 143-00 (2000) Standard test method for slump of hydraulic cement concrete.

22. ASTM C231-04 (2004) Standard test method for Air Content of freshly mixed concrete by the pressure method.

23. ASTM C39-01 (2001) Standard test method for compressive strength of cylindrical concrete specimens.

24. UNE-EN 1239-08 (2001) Testing hardened concrete - Part 8: depth of penetration of water under pressure.

25. ASTM C496-90 (1990) Standard test method for splitting tensile strength of cylindrical concrete specimens.

26. ASTM C469-87a. (1987) Standard test method for static modulus of elasticity and poisson's ratio of concrete in compression.

27. Romero, H.L. (2011) Deterioro del hormigón sometido a ensayos acelerados de hielo-deshielo en presencia de cloruros. Ph.D. Thesis. Universidad Politécnica Madrid.

28. ASTM D4404-84 (2004) Standard test method for determination of pore volume and pore volume distribution of soil and rock by mercury intrusion porosimetry.

29. Pane, I.; Hansen, W. (2005) Investigation of blended cement hydration by isothermal calorimetry and thermal analysis. Cem. Concr. Res. 35, 1155-1164. http://dx.doi.org/ 10.1016/i.cemconres.2004.10.027.

30. Sabir, B.B. (1997) Mechanical Properties and Frost Resistance of Silica fume Concrete. Cem. Concr. Comp. 19 , 285-294.http://dx.doi.org/10.1016/S0958-9465(97)00020-6.

31. Mirza, F.A.M.; Al-Mukarramah, M. (2009) Effect of Sand Replacement and Silica Fume Addition on Chloride Ion Permeability of Lightweight Concrete. JKAU: Engineering Science, 61-73.
32. Kearsley, E.P.; Wainwright, P.J. (2001) Porosity and permeability of foamed concrete. Cem. Concr. Res. 31, 805-812. http://dx.doi.org/10.1016/S0008-8846(01)00490-2.

33. Neville, A.M. (1999) Properties of Concrete, Fourth and Final Edition, Pearson education limited, England, 433-528.

34. Powers, T.C. (1968) The Properties of Fresh Concrete, John Wiley and Sons, Inc.; New York, 1968.

35. Detwiler, R.J.; Mehta, P.K. (1989) Chemical and physical effects of silica fume on the mechanical behavior of concrete. ACI Mater. J. 86 [6], 609-614.

36. Scrivener, K.L.; Crumbie, A.K.; Laugesen, P. (2004) The interfacial transition zone (ITZ) between cement paste and aggregate in concrete. Interface. Science, 12, 411-421. http:// dx.doi.org/10.1023/B\%3AINTS.0000042339.92990.4c.

37. Bishnoi, S.; Uomoto, T. (2008) Strain-temperature hysteresis in concrete under cyclic freeze-thaw conditions. Cem. Concr. Comp., 30, 374-380. http://dx.doi.org/10.1016/j. cemconcomp.2008.01.005.

38. Jacobsen, S.; Lindgård, J.; Fritz, L. (2008) In: Frost dilation measurements on concrete cores from a dam with ASR. 13th ICAAR conference proceedings; Trondheim. 131-142.

39. Penttala, V.; Al-Neshawy, F. (2002) Stress and strain state of concrete during freezing and thawing cycles. Cem. Concr. Res. 32 [9], 1407-1420. http://dx.doi.org/10.1016/S0008-8846 (02)00785-8.

40. Hasan, M.; Sato, Y.; Ueda, T. (2008) Stress-strain relationship of frost-damaged concrete subjected to fatigue loading. Journal of Materials in Civil Engineering, 20-37. http:// dx.doi.org/10.1061/(ASCE)0899-1561(2008)20:1(37).

41. Aligizaki, K.K. (2006) Pore Structure of Cement-Based Materials, Testing, Interpretation and Requirements, Abingdon, Oxford, Taylor \& Francis.

42. Klemm, A.J.; Klemm, P. (1997) The effects of the alternate freezing and thawing cycles on the pore structure of cementitious composites modified by MHEC and PVA. Build. Environ. 23 [6], 509-512. http://dx.doi.org/10.1016/ S0360-1323(97)00025-5.

43. Lea, F.M. (1974) The chemistry of cement and concrete. $4^{\text {th }}$ ed. Edward Arnold.

44. Ubbraco, P.; Calabrese, D. (1998) Solidification and stabilization of cement paste containing fly ash from municipal waste. Thermochimica acta, 321 [1, 2], 143. http://dx.doi. org/10.1016/S0040-6031(98)00453-5. 